\title{
Immunohistochemical Localization of Neuronal Nicotinic Receptors in the Rodent Central Nervous System
}

\author{
L. W. Swanson, ${ }^{1,2}$ D. M. Simmons, ${ }^{1,2}$ P. J. Whiting, ${ }^{1}$ and J. Lindstrom ${ }^{1}$ \\ 1The Salk Institute for Biological Studies, and ${ }^{2}$ Howard Hughes Medical Institute, La Jolla, California 92037
}

The distribution of nicotinic acetylcholine receptors (AChR) in the rat and mouse central nervous system has been mapped in detail using monoclonal antibodies to receptors purified from chicken and rat brain. Initial studies in the chicken brain indicate that different neuronal AChRs are contained in axonal projections to the optic lobe in the midbrain from neurons in the lateral spiriform nucleus and from retinal ganglion cells. Monoclonal antibodies to the chicken and rat brain AChRs also label apparently identical regions in all major subdivisions of the central nervous system of rats and mice, and this pattern is very similar to previous reports of ${ }^{3} \mathrm{H}$-nicotine binding, but quite different from that of $\alpha$-bungarotoxin binding. In several instances, the immunohistochemical evidence has strongly indicated that neuronal AChR undergoes axonal transport. The clearest example of this has been in the visual system, where labeling was observed in the retina, the optic nerve and tract, and in all of the major terminal fields of the optic nerve except the ventral suprachiasmatic nucleus. This was confirmed in unilateral enucleation experiments in the rat, where labeling was greatly reduced in the contralateral optic tract, ventral lateral geniculate nucleus, pretectal nuclei receiving direct visual input, superficial layers of the superior colliculus, and medial terminal nucleus, and was significantly reduced in the dorsal lateral geniculate nucleus. Clear neuronal labeling was also observed in dorsal root ganglion cells and in cranial nerve nuclei containing motoneurons that innervate branchial archderived muscles, although the possibility that neuronal AChR undergoes axonal transport in the latter cells was not tested experimentally. The possibility that neuronal AChRs may act both pre- and postsynaptically in the nervous system is discussed.

Acetylcholine $(\mathrm{ACh})$ is a classical neurotransmitter that plays an important signaling role in many parts of the nervous system, and, like several other neurotransmitters, it is known to interact with different pharmacologically defined classes of receptors. Muscarinic $\mathrm{ACh}$ receptors act through second messengers and

Received Feb. 6, 1987; revised May 8, 1987; accepted May 8, 1987.

We thank John Cooper for iodinations, Ru Shya Liu who grew the mAbs and helped clone them, Dr. H. Karten for helpful discussions, and K. Trulock for photographic printing. This work was partly supported by NIH Grants NS16686 (L.W.S) and NS11323, the Muscular Dystrophy Association, U.S. Army Grant DAMD-17-86-C-6148, the Alexander Onassis Public Benefit Foundation, and the Los Angeles and California Chapter of the Myasthenia Gravis Foundation (J.L.) P.W. was supported by an MDA postdoctoral fellowship.

Correspondence should be addressed to Dr. L. W. Swanson, Neural Systems Laboratory, The Salk Institute, P.O. Box 85800, San Diego, CA 92138-9216.

Copyright (c) 1987 Society for Neuroscience $0270-6474 / 87 / 103334-09 \$ 02.00 / 0$ are structurally unrelated (Kubo et al., 1986a, b) to nicotinic ACh receptors (AChR; Noda et al., 1983a, b), which act by regulating directly the opening of a cation channel that is an intrinsic component of the molecule. Furthermore, subtypes of neuronal AChRs have been identified on the basis of pharmacological and structural properties (Whiting et al., 1987a). To understand the functional significance of $\mathrm{ACh}$ in a particular neural system, it is therefore necessary to establish the cellular localization of $\mathrm{ACh}$, and the cellular localization and type of cholinergic receptor with which it interacts. Immunohistochemistry provides a sensitive method for localizing cholinergic neurons with antibodies to the synthetic enzyme choline acetyltransferase, whereas the distribution of cholinergic receptors in tissue sections has largely been characterized autoradiographically, using radiolabeled cholinergic ligands.

The structure of AChRs from fish electric organs and skeletal muscle has been greatly clarified with the biochemical characterization of their protein subunits $(\alpha, \beta, \gamma, \delta)$, and the scquencing of their respective cDNAs (Popot and Changeux, 1984; McCarthy et al., 1986). $\alpha$-Bungarotoxin ( $\alpha \mathrm{Bgt})$ has been an extremely useful probe for AChRs from these tissues, but there are neuronal AChRs that are not blocked by $\alpha \mathrm{Bgt}$ and neuronal $\alpha \mathrm{Bgt}$ binding sites that are not neuronal AChRs (see Patrick and Stallcup, 1977; Jacob et al., 1984; Whiting and Lindstrom, 1987a; Whiting et al., 1987a), which suggests that $\alpha$ Bgt may not always be a good probe for characterizing neuronal AChRs. Antibodies have also been useful probes for AChRs (Lindstrom, 1986), and some monoclonal antibodies (mAbs) to AChRs from electric organs and muscle bind to neuronal AChRs that do not bind $\alpha \mathrm{Bgt}$ (Whiting and Lindstrom, 1986a, b), indicating that they may provide ideal probes for these neuronal receptors. Whiting and Lindstrom have recently immunoaffinity-purified neuronal AChRs from chicken (1986a, b) and rat (1987a) brain that are clcarly distinct from brain $\alpha \mathrm{Bgt}$-binding proteins described earlier (Conti-Tronconi et al., 1985; Kemp et al., 1985), since they fail to bind $\alpha \mathrm{Bgt}$. Two AChR subtypes have been identified in the chicken brain; they exhibit identical high-affinity, stereospecific binding for $\mathrm{L}$-nicotine, and have similar or identical $\alpha$-subunits $\left(M_{\mathrm{r}}=49,000\right)$, but differ in their $\beta$-subunits $\left(\beta, M_{\mathrm{r}}=\right.$ 59,000 or $\beta^{\prime}, 75,000$ ) (Whiting et al., 1987a). Antisera to the chicken neuronal AChRs specifically block ACh-induced depolarization of chick ciliary ganglion cells (Stollberg et al., 1986) and bind virtually all of the high-affinity nicotine binding sites in brain extracts (Whiting and Lindstrom, 1986b). Several mAbs have been raised to the chicken neuronal $A C h R$, one of which (mAb 270) also cross-reacts with an AChR from rat brain. This mAb also binds $>90 \%$ of the high-affinity $\left(K_{\mathrm{d}}=1.5 \mathrm{nM}\right)$ nicotine binding sites in detergent extracts of rat brain (Whiting and 

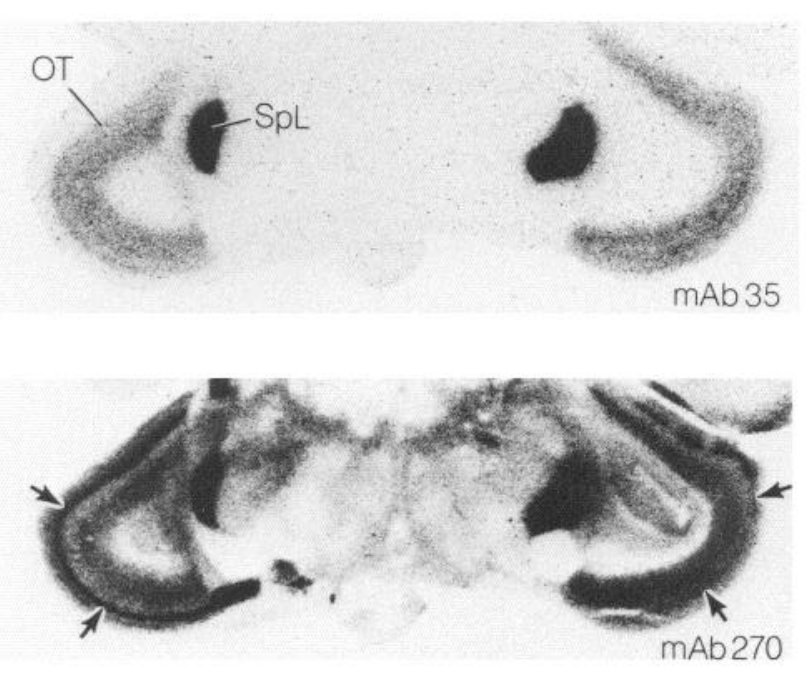

Figure 1. Adjacent frontal sections through the chick midbrain showing the pattern of ${ }^{125} \mathrm{I}-\mathrm{mAb}-35$ and ${ }^{125} \mathrm{I}-\mathrm{mAb}-270$ immunolabeling. Both $\mathrm{mAbs}$ heavily labeled the lateral spiriform nucleus $(S p L)$ and its projection to the optic lobe $(O T)$. mAb 270 also labeled other regions of the midbrain, including layer $f$ of the superficial tectum (arrows). The left eye was removed at 3 weeks of age and the animal was killed 1 month later; note that $\mathrm{mAb}-270$ labeling on the right side of layer $f$ is greatly reduced. $\times 6$.

Lindstrom, 1986b) and binds to agonist-sensitive cation channels in rat neuron-like PC12 cells (Whiting et al., 1987b), but does not bind to muscle AChRs (Whiting and Lindstrom, 1986b). Neuronal AChRs immunoaffinity-purified from rat brain using $\mathrm{mAb} 270$ also revealed 2 subunits $\left(\alpha, M_{\mathrm{r}}=51,000\right.$ and $\beta^{\prime}, M_{\mathrm{r}}=$ 79,000 ) with mAb 270 binding to the $\alpha$-subunit (Whiting and Lindstrom, 1987a). Both subtypes of neuronal AChR from chicken brain and the neuronal AChR from rat brain can be affinity-labeled with bromoacetylcholine and 4- $(N$-maleimido $)$ benzyltrimethyl ammonium iodide (MBTA), suggesting that residues homologous to cysteines 192-193 in the $\alpha$-subunit of Torpedo AChR have been conserved (Whiting and Lindstrom, 1987b). It is interesting that what we have called the $\beta$-subunit of the brain neuronal AChR because of its molecular weight contains the ACh binding site (Whiting and Lindstrom, 1987b).

Because there is now a substantial body of evidence that $\mathrm{mAb}$ 270 is a specific probe for localizing functional neuronal $\mathrm{AChRs}$, we examined immunohistochemically its binding throughout the CNS of the rat and mouse. We also compared this to the pattern of immunolabeling with mAb 290, which was prepared from rats immunized with rat brain AChR immunoaffinitypurified upon mAb 270-Sepharose. Like mAb 270, mAb 290 binds the high-affinity nicotine binding sites in rat brain and, when coupled to Sepharose, affinity-purifies a neuronal AChR with a subunit structure identical to that of receptor purified on mAb 270-Sepharose (P. J. Whiting and J. Lindstrom, unpublished observations).

\section{Materials and Methods}

One-month-old white Leghorn chickens, adult Sprague-Dawley rats, and adult $\mathrm{Balb} / \mathrm{c}$ mice were used in these experiments.

For all of the immunohistochemistry in this paper, the animals were decapitated and tissue was removed and frozen with liquid nitrogen.
Cryostat sections (20 $\mu \mathrm{m}$ thick) were thaw-mounted onto slides and desiccated at $0-4^{\circ} \mathrm{C}$ under vacuum overnight (Herkenham and Pert, 1982). For autoradiographic localization, the sections were overlaid with $4 \mathrm{nM}{ }^{125} \mathrm{I}-\mathrm{mAb} 270$ (radioiodinated to a specific activity of 1-2 $\times$ $10^{18} \mathrm{cpm} / \mathrm{mol}$ by a modified chloramine-T method; Lindstrom et al., 1981 ) in $100 \mathrm{~mm} \mathrm{NaCl}, 10 \mathrm{~mm}$ Na phosphate buffer, pH 7.5, $10 \mathrm{~mm}$ $\mathrm{NaN}_{3}, 10 \%$ normal rat serum, and $5 \%$ dried milk (Carnation), and were incubated overnight at $4^{\circ} \mathrm{C}$. ${ }^{125} \mathrm{I}-\alpha \mathrm{Bgt}\left(4 \mathrm{~nm}\right.$; sp act, $2-4 \times 10^{17} \mathrm{cpm} /$ mol) was also used in this way, except that dried milk was eliminated from the buffer. The slides were transferred to Coplin jars and rinsed 5 times over $30 \mathrm{~min}$ with $100 \mathrm{~mm} \mathrm{NaCl}, 10 \mathrm{~mm}$ Na phosphate buffer, $\mathrm{pH} 7.5$, and $10 \mathrm{~mm} \mathrm{NaN}_{3}$ at room temperature. The sections were further rinsed in 3 changes of buffer over $3 \mathrm{hr}$ on a rocking platform at $4^{\circ} \mathrm{C}$. They were then dried at $37^{\circ} \mathrm{C}$, mounted on cardboard in groups of 20 , overlaid with an $8 \times 10$ in. sheet of Kodak XAR5 (or Dupont Cronex) film in a cassette, and autoradiographed at room temperature for 12$36 \mathrm{hr}$ (or 2-6 d for Cronex). The sections were then postfixed in $10 \%$ formalin, dehydrated in ethanol, defatted in xylene, rehydrated and airdried, dipped in Kodak NTB-2 emulsion, exposed for $4 \mathrm{~d}$, and developed as described elsewhere (Sawchenko and Swanson, 1983). For indirect immunofluorescence, sections were obtained as described above, and the $\mathrm{mAbs}$ were localized with goat anti-rat IgG conjugated with fluorescein isothiocyanate (FITC) as described elsewhere (Swanson et al., 1983b).

$\mathrm{mAb} 270$ was prepared from rats immunized with immunoaffinitypurified AChR from chicken brain. Its preparation and characterization are described in detail elsewhere (Whiting et al., 1987a).

\section{Results}

\section{Immunolabeling in chicken brain}

We previously found in the chick midbrain that mAbs to AChRs from electric organ and muscle stain neurons in the lateral spiriform nucleus $(\mathrm{SpL})$, along with their axonal projections to deeper layers of the optic lobe (Swanson et al., 1983a). Since one of these mAbs (mAb 35) was used to purify AChRs from chicken brain (to which mAb 270 was subsequently raised), we first compared immunolabeling patterns from mAb 35 and $\mathrm{mAb}$ 270. Both $\mathrm{mAbs}$ labeled the $\mathrm{SpL}$ and deeper layers of the optic lobe, whereas mAb 270 labeled additional parts of the midbrain, with a particularly obvious dense band over layer $f$ in the stratum griseum et fibrosum superficialis of the optic lobe (Fig. 1). Interestingly, unilateral removal of one eye eliminated the ventral two-thirds of this dense band of labeling in the contralateral optic tectum (and in the contralateral optic tract), but left the pattern of mAb 35 labeling unaltered (Fig. 1). Enucleation also reduced ${ }^{125} \mathrm{I}-\alpha \mathrm{Bgt}$ binding in the contralateral layer $\mathrm{f}$, but not in layers innervated by the SpL (not illustrated; see Brecha et al., 1979). These results indicate that $\mathrm{mAb} 270$ and $\mathrm{mAb} 35$ have an identical distribution in the $\mathrm{SpL}$, and biochemical evidence indicates that they recognize the same antigen (Whiting et al., 1987a), and suggests that mAb 270 recognizes a second AChR in retinal ganglion cells that project to superficial tectal layer $\mathrm{f}$. And since both chicken brain AChRs that cross-react with mAb 270 do not bind $\alpha$ Bgt (Whiting and Lindstrom, 1986a; Whiting et al., 1987a), it appears that retinal ganglion cell terminals in layer $\mathrm{f}$ may contain both a neuronal AChR and an $\alpha$ Bgt-binding protein. In chick ciliary ganglion neurons, mAb 35 binds to synaptic membranes, whereas $\alpha$ Bgt binds to extrasynaptic regions of neuronal membranes and does not block ACh-induced depolarization (Jacob et al., 1984).

\section{Overview: Immunolabeling, $\alpha$ Bgt binding, and nicotine binding in rodent $C N S$}

${ }^{125} \mathrm{I}-\mathrm{mAb} 270$ was next used to characterize the distribution of neuronal AChRs in tissue sections throughout the rostrocaudal 

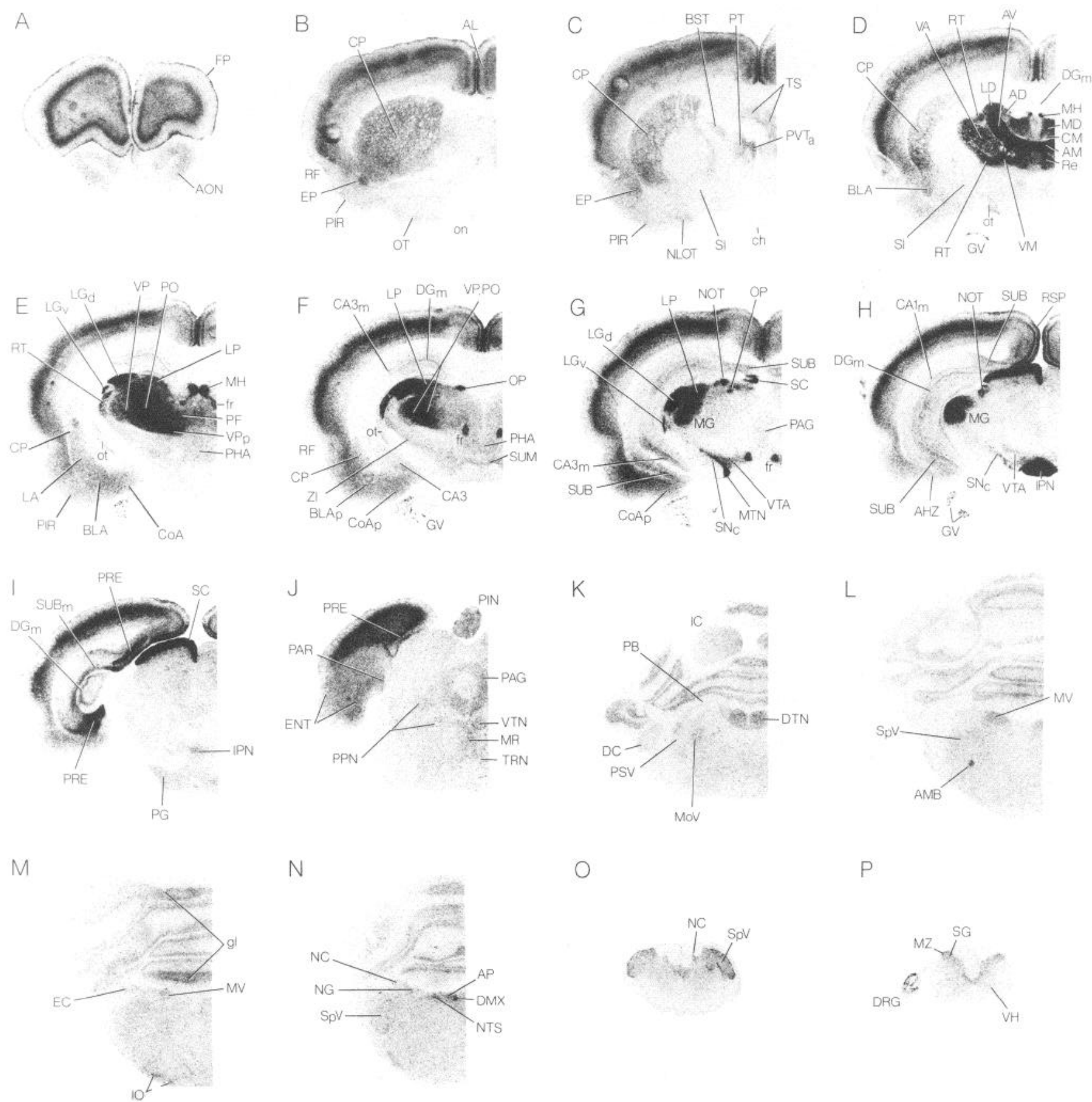

$\mathrm{P}$
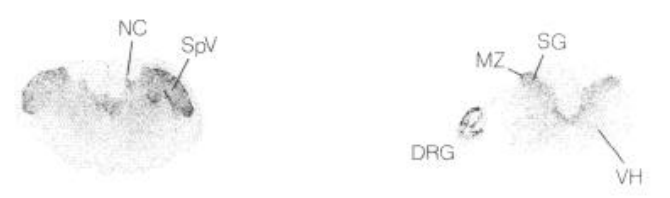

Figure 2. The distribution of ${ }^{125} \mathrm{I}-\mathrm{mAb}-270$ immunolabeling in a rostrocaudal $(A-P)$ series of sections through the rat CNS. Virtually no labeling was observed when the sections were coincubated in $400 \mathrm{~nm}$ cold mAb 270 . Adjacent Nissl-stained sections were used to identify labeled structures. From an enucleated (left eye) animal (see text and Figs. 4, 6). $\times 1.8$. Immunolabeled regions: $A D$, anterodorsal nucleus (n.); $A H Z$, amygdalohippocampal area (a.); $A L$, anterior limbic a.; $A M$, anteromedial n.; $A M B$, n. ambiguus; $A O N$, anterior olfactory n.; $A P$, a. postrema; $A V$, anteroventral n.; BLAp, basolateral n. amygdala (posterior); $B S T$, bed n. stria terminalis; $C A 1 m-C A 3 m$, molecular layer of Ammon's horn fields; $C M$, central medial n.; CoAp, cortical n. amygdala (posterior); $C P$, caudoputamen; $D C$, dorsal cochlear n.; $D G m$, dentate gyrus molecular layer; $D M X$, dorsal motor n. vagus; $D R G$, dorsal root ganglion; $D T N$, dorsal tegmental n.; $E C$, external cuneate n.; $E N T$, entorhinal a.; $E P$, endopyriform n.; $F P$, frontal pole; $G V$, trigeminal ganglion; $I C$, inferior colliculus; $I O$, inferior olive; $I P N$, interpeduncular n.; $L A$, lateral n. amygdala; $L D$, lateral dorsal $\mathrm{n}$.; $L G, d, v$, dorsal, ventral lateral geniculate $\mathrm{n}$.; $L P$, lateral posterior $\mathrm{n}$.; $M D$, mediodorsal $\mathrm{n}$.; $M G$, medial geniculate $\mathrm{n}$.; $M H$, medial habenula; $M O V$, motor n., trigeminal; $M R$, median raphe; $M V$, medial vestibular $\mathrm{n}$.; $M Z$, marginal zone; $N C$, cuneiform $\mathrm{n}$.; $N G$, gracile $\mathrm{n}$.; $N L O T$, $\mathrm{n}$. lateral olfactory tract; $N O T, \mathrm{n}$. optic tract; $N T S$, n. solitary tract; $O P$, olivary pretectal n.; $O T$, olfactory tubercle; $P A G$, periaqueductal gray; $P A R$, parasubiculum; $P B$, parabrachial n.; $P F$, parafascicular n.; $P G$, pontine gray; $P H A$, posterior hypothalamic a.; $P I N$, pineal; $P I R$, piriform cortex; $P O$, posterior complex; $P P N$, pedunculopontine n.; $P R E$, presubiculum; $P S V$, sensory n., trigeminal; $P T$, paratenial $\mathrm{n}$.; $P V T a$, paraventricular $\mathrm{n}$. thalamus (anterior); $R e$, n. reuniens; $R f$, rhinal fissure; $R S P$, retrosplenial a.; $R T$, reticular $\mathrm{n}$.; $S C$, superior colliculus; $S G$, substantia gelatinosa; $S I$, substantia innominata; $S N c$, compact part, substantia nigra; $S p V$, spinal n. trigeminal; $S U B(m)$, subiculum (molecular layer); $T R N$, tegmental reticular n.; $T S$, triangular $\mathrm{n}$. septum; $V A$, ventral anterior $\mathrm{n}$.; $V H$, ventral horn; $V M$, ventromedial n., thalamus; $V P p$, ventral posterior $\mathrm{n}$. (parvicellular); $V T A$, ventral tegmental a.; $V T N$, ventral tegmental n.; $Z I$, zona incerta. $c h$, Optic chiasm; $f r$, fasciculus retroflexus; $g l$, granular layer cerebellum; on, optic nerve; ot, optic tract. 


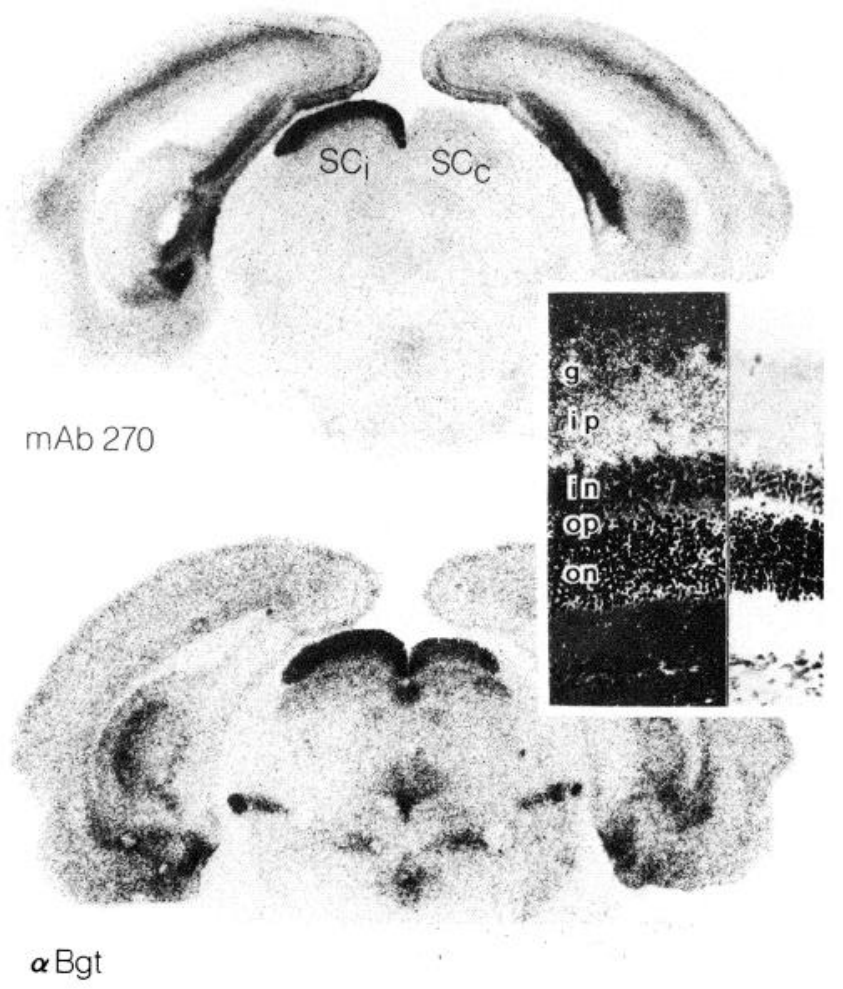

Figure 3. Effect of left enucleation 3 weeks prior to death on ${ }^{125} \mathrm{I}-\mathrm{mAb}$ 270 immunolabeling (top) and ${ }^{125} \mathrm{I}-\alpha \mathrm{Bgt}$ binding (bottom) in adjacent sections of the rat superior colliculus $(S C)$. Note disappearance of $\mathrm{mAb}$ 270 labeling in the contralateral SC $(S C c)$ and dense labeling in the ipsilateral SC $(\mathrm{SC} i)$ of this slightly asymmetrically cut section. $\times 5$. Inset, dark-field photomicrograph (left) of ${ }^{125} \mathrm{I}-\mathrm{mAb} 270$ immunolabeling in the ganglion cell layer $(g)$ and inner plexiform layer $(i p)$ of the rat retina. Labeling is particularly dense in the deep part of the ip. Apparent labeling in the outer nuclear layer (on) is artifactual, due to cracks between densely packed cells. Bright-field view (right) of Nissl stain. in, Inner nuclear layer; $o p$, outer plexiform layer. $\times 75$.

extent of the rat CNS. This was necessary because mAb 35 has a very low affinity for rat brain $\mathrm{AChR}$ (Whiting and Lindstrom, 1986b), and we were unable to confirm histochemically a report that this $\mathrm{mAb}$ binds to cells in the rodent supraoptic and paraventricular nuclei (Mason, 1985). Immunolabeling with $\mathrm{mAb}$ 270 was localized to discrete regions at all levels of the brain and spinal cord (Fig. 2), and this pattern was identical to that of published maps of ${ }^{3} \mathrm{H}$-nicotine binding in the rat forebrain and midbrain (Clarke et al., 1985a). Adjacent sections incubated in ${ }^{125} \mathrm{I}-\alpha \mathrm{Bgt}$ revealed a quite different pattern of labeling (Fig. 3 ), which was also identical to that reported in the rat forebrain and midbrain (Clarke et al., 1985a). The immunolabeling specificity was confirmed by incubating adjacent sections in ${ }^{125} \mathrm{I}$ $\mathrm{mAb} 290$, and a pattern similar to that for mAb 270 was observed. A similar pattern of labeling with $\mathrm{mAb} 270$ was also observed in the mouse brain (Fig. $4 C$ ). Taken together, this evidence indicates that both $\mathrm{mAb} 270$ and $\mathrm{mAb} 290$ produce a labeling pattern that corresponds precisely to nicotine binding sites in the rodent CNS, but not to $\alpha$ Bgt binding sites. This confirms biochemical data showing that $\mathrm{mAb} 270$ (Whiting and Lindstrom, 1986b, 1987a) and mAb 290 (P. J. Whiting and J. Lindstrom, unpublished observations) bind virtually all of the high-affinity ${ }^{3} \mathrm{H}$-nicotine binding sites in detergent extracts of rat brain, but do not interact with ${ }^{125} \mathrm{I}-\alpha$ Bgt binding sites. Because these immunohistochemical studies (Fig. 2) are more extensive than were earlier reports based on ${ }^{3} \mathrm{H}$-nicotine binding histochemistry, new insights into the central distribution of neuronal AChRs emerged.

\section{Retinal projections to the brain}

The retina contains cholinergic amacrine cells (Voigt, 1986) that excite specific classes of ganglion cells by way of AChRs (Ariel and Daw, 1982; Ikeda and Sheardown, 1982; Pazdernik et al., 1982), which are not blocked by $\alpha$ Bgt (Lipton et al., 1986). It was not surprising, therefore, that dense mAb 270 labeling was restricted to the inner plexiform layer of the retina (Fig. 3), which contains synapses between amacrine cell processes and ganglion cell dendrites. Distinct immunolabeling was also observed over the optic nerve and tract, and dense labeling occurred in all but one region innervated by retinal ganglion cellsthe dorsal and ventral lateral geniculate nucleus, nucleus of the optic tract, and olivary nucleus of the pretectal region, superficial layers of the superior colliculus (optic tectum), and medial terminal nucleus of the basal optic root-whereas the ventral suprachiasmatic nucleus was unlabeled (Figs. 2, 4). Since both retinal ganglion cell dendrites and axons were labeled, this evidence suggests that subpopulations of retinal ganglion cells synthesize neuronal AChRs that are transported to their dendrites, and through their axons to the brain. Consistent with this interpretation, unilateral enucleation experiments $(n=6)$ with a survival time of 2-4 weeks demonstrated that immunolabeling was eliminated in the unilateral optic nerve and was greatly reduced in the contralateral optic tract, ventral lateral geniculate nucleus (Fig. 5), pretectal nuclei, superior colliculus (Fig. 3), and medial terminal nucleus. Labeling in the dorsal lateral geniculate nucleus was clearly reduced, but not as dramatically (Fig. 5). These results are consistent with the fact that the optic tract is some $90-95 \%$ crossed in the rat (Hayhow et al., 1962), and with the possibility that the dorsal lateral geniculate nucleus also contains neuronal $\mathrm{AChR}$ from another source, either intrinsic cells or axon terminals. $\alpha$ Bgt binding in the contralateral superior colliculus of enucleated animals appeared to be only very slightly reduced (Fig. 3), suggesting that little, if any, $\alpha$ Bgt-binding protein is transported from the retina in the optic nerve of the rat. It now seems likely that in the goldfish an AChR that binds both $\alpha$ Bgt and some mAbs to electric organ AChRs is transported to the tectum by retinal ganglion cells (Henley et al., 1986), that in the chicken separate neuronal $\mathrm{AChR}$ and $\alpha \mathrm{Bgt}-$ binding proteins undergo similar transport, and that in the rodent this transport is largely restricted to a neuronal AChR.

\section{Other sensory systems}

Dorsal root ganglion cells give rise to a single process that divides and sends one branch to the periphery and one to the spinal cord. Some of these cells bind $\alpha$ Bgt (Polz-Tejera et al., 1980) and stain for AChE (Kokko, 1965), and we found that a subpopulation of these neurons (both small and large) also stains with $\mathrm{mAb} 270$ (Fig. $2 P$ ), as do ganglion cells in the trigeminal ganglion (Fig. 5) and mesencephalic nucleus of the trigeminal. As with retinal ganglion cells, it appears that neuronal $\mathrm{AChR}$ may undergo axonal transport, because dense label was found over the dorsal horn (particularly the marginal zone; Fig. $2 P$ ), and lighter label was found in other terminal fields of the central processes, including the dorsal horn, dorsal column nuclei (Fig. 

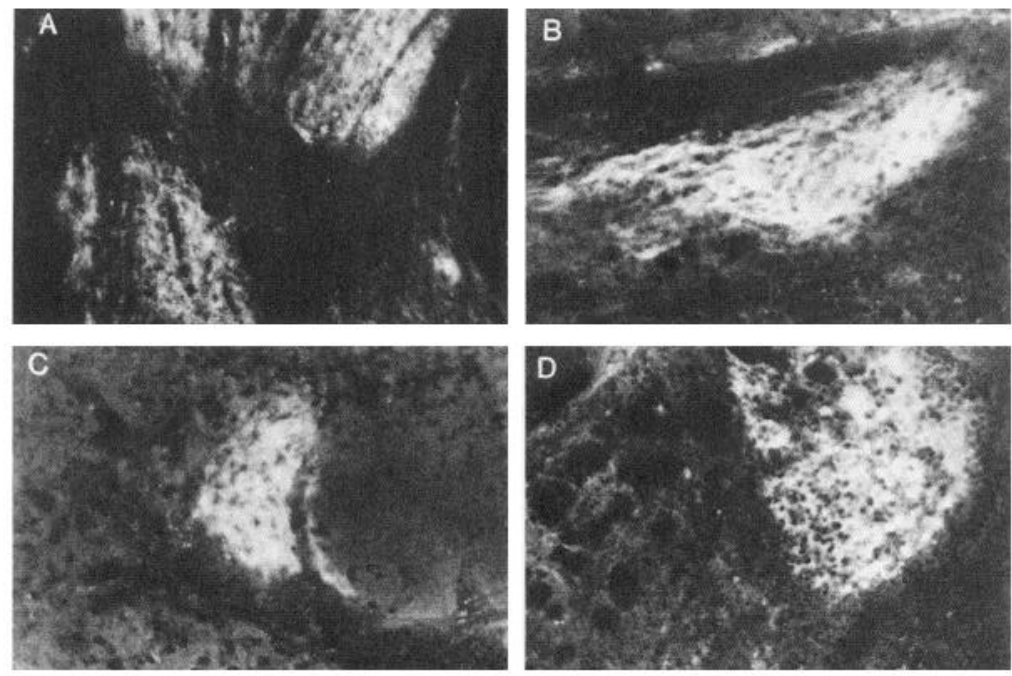

Figure 4. Photomicrographs showing the indirect immunofluorescence localization of $\mathrm{mAb} 270(A, B, D)$ and $\mathrm{mAb} 290(C)$ in the mouse brain. $A$, Dorsal (top) and ventral (bottom) lateral geniculate nucleus; compare with Figure $2 F$. $B$, Olivary pretectal nucleus; compare with Figure $2 F$. $C$, Right medial terminal nucleus; compare with Figure $2 G . D$, Medial habenula with unlabeled lateral habenula and stria medullaris to the left; compare with Figure 2, $D, E$. Because the fasciculus retroflexus and interpeduncular nucleus were clearly labeled (Fig. $2, E-I)$, it appears likely that neuronal AChR is synthesized in medial habenular cells (Clarke et al., 1985a, 1986; Goldman et al., 1986) and undergoes axonal transport to the interpeduncular nucleus. Indirect immunofluorescence was only successful in the mouse, probably because the primary mAbs were raised in rats, where background staining was high, and was not sensitive enough to reveal areas moderately or lightly labeled with ${ }^{125} \mathrm{I}-\mathrm{mAbs}$, such as the cerebral cortex. All micrographs $\times 75$.

$2 N$ ), and the sensory nuclei of the trigeminal (Fig. $2, K, O$ ). The peripheral endings of a variety of sensory fibers are sensitive to ACh through an AChR (Gray, 1959; Paintal, 1964), and the central endings in the spinal cord may contain presynaptic AChRs (Esplin et al., 1972), whereas cell bodies themselves are not sensitive to ACh (DeMontigny and Lund, 1980; Karczmar et al., 1980).

Other sensory neurons were not examined directly, although apparent terminal fields and/or cells were labeled in the nucleus of the solitary tract and area postrema (central ending of vagal and glossopharyngeal ganglion cells, which may synthesize AChRs; Cooper and Lau, 1986), medial vestibular nucleus, and cochlear nuclei. The olfactory bulb glomeruli were unlabeled, although the inner plexiform layer was moderately labeled. Further experimental work is needed to demonstrate whether neuronal $\mathrm{AChRs}$ are transported in sensory neuron processes.

\section{Motor nuclei}

Clear labeling was observed over large neurons in 4 motor nuclei: the trigeminal motor nucleus (Fig. $2 K$ ), facial nucleus, nucleus ambiguus (Fig. $2 L$ ), and dorsal motor nucleus of the vagus (Fig. $2 N$ ). It is of interest that the first 3 innervate branchial arch-derived skeletal muscle, whereas the fourth contains preganglionic parasympathetic neurons. Motor neurons innervating the extraocular muscles (oculomotor, trochlear, and abducens nuclei) may be very lightly labeled, whereas labeling over motor neurons in the hypoglossal nucleus and spinal ventral horn was near background levels. This evidence suggests that certain motor neurons may receive a nicotinic cholinergic input, as has been reported for the nucleus ambiguus ( $\mathrm{Wu}$ and Martin, 1983), although it remains to be demonstrated whether these neurons transport neuronal AChRs to their axon terminals in the facial musculature, the muscles of mastication, and the muscles of the pharynx, larynx, and esophagus.

Several other "premotor" regions were also clearly labeled, including the cerebellar granular layer (particularly lobules 9 and 10 ) and regions that project to the cerebellum, including the deep pontine gray (Fig. $2 I$ ), tegmental reticular nucleus (Fig. $2 J$ ), inferior olive (Fig. $2 M$ ), and nucleus prepositus. The pedunculopontine nucleus (mesencephalic locomotor region) was lightly labeled, as were neurons in the superior vestibular nucleus that presumably project to the spinal cord. The caudoputamen was moderately labeled (Fig. 2, $B-D$ ), which was almost certainly due to axonal transport, since many presumably dopaminergic neurons were labeled in the compact part of the substantia nigra (Fig. 2, $G, H$ ), and the region of the nigrostriatal tract was labeled. Similarly, many (presumably dopaminergic) neurons in the ventral tegmental area were also labeled (Fig. 2, $G, H$ ), along with the associated terminal field in the nucleus accumbens.

\section{Ventrolateral medulla}

Nicotine applied to the ventrolateral surface of the medulla acts on a subadjacent "chemosensitive" zone to produce a fall in systemic blood pressure (Feldberg and Guertzenstein, 1976). In agreement with these physiological results, a limited region of the ventrolateral medulla (ventral to the spinal nucleus of the trigeminal) was immunolabeled with mAb 270 (Fig. $2 N$ ).

\section{Forebrain}

As with ${ }^{3} \mathrm{H}$-nicotine binding (Clarke et al., 1985b), all thalamic nuclei (except the lateral habenula) were clearly labeled with our mAbs (see Fig. 2 for relative density). In the neocortex, labeling was generally centered over layers Ia, IV, and deeper parts of $\mathrm{V}$, whereas in the cingulate gyrus and medial prefrontal cortex, label was concentrated over layers I, III, and V-VI (Fig. 6). This pattern was quite different in olfactory cortex, where labeling was centered in layer II of the anterior olfactory nucleus and nucleus of the lateral olfactory tract, and in layer III of the pyriform cortex and olfactory tubercle. In the hippocampal for- 

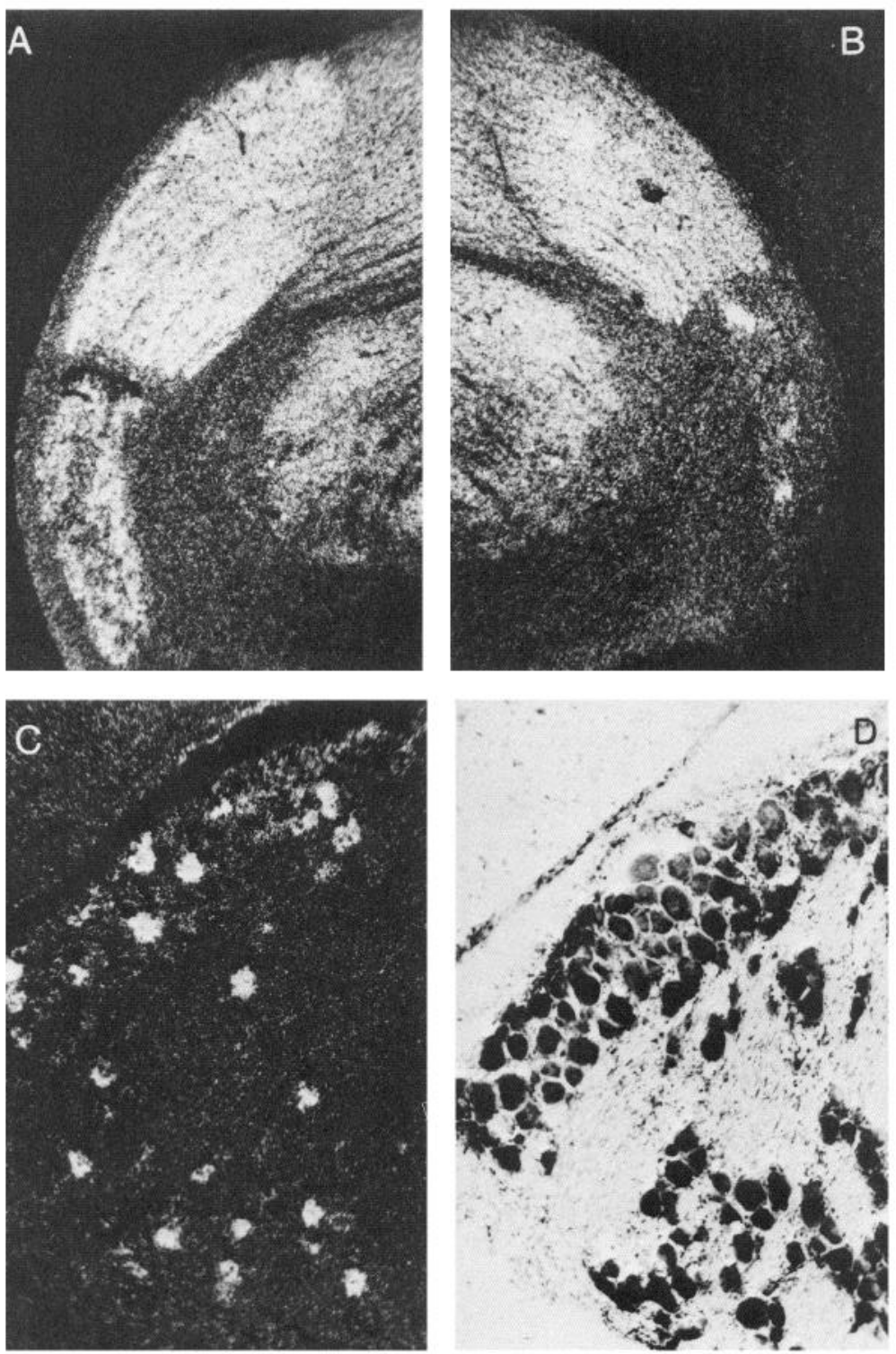

Figure 5. A, B, Dark-field photomicrographs of ${ }^{125}$ I-mAb 270 immunolabeling in the lateral geniculate nucleus on the side ipsilateral $(A)$ and contralateral $(B)$ to enucleation in the rat illustrated in Figure 3; comparable to $F$ in Figure 2. See text for details. $\times 30$. $C$, Dark-field photomicrograph of ${ }^{125} \mathrm{I}-$ $\mathrm{mAb} 270$ immunolabeled ganglion cells in the trigeminal ganglion (see Fig. 2, $E-G) . D$, Nissl-stained section adjacent to $C$. $C, D, \times 100$. mation (Figs. 2, $E, J ; 7$ ), label was most dense over the molecular layer of Ammon's horn and the middle third of the dentate molecular layer (like the medial perforant pathway from the entorhinal area), the molecular layer and deep pyramidal layer of the subiculum, layers I-III of the presubiculum, layer I of the parasubiculum, and layer IV (and, to a lesser extent, layers I and II) of the entorhinal area. Interestingly, the densest labeling in the thalamus is in the anterior group, which projects specifically to layers I-III of the presubiculum (Shipley and Sorensen, 1975). The lateral and basolateral nuclei of the amygdala were more densely labeled than the cortical nucleus, and the medial nucleus was only lightly labeled; no obvious labeling was found over the central and posterodorsal medial nuclei (Fig. 2, $D-G$ ). The triangular nucleus and posterodorsal bed nucleus were the only clearly labeled structures in the septal region (Fig. 2G). Light labeling was seen over the substantia innominata or ventral pallidum (Fig. 2, C, D), which contains a population of cholinergic neurons that innervates the entire neocortex. Finally, the pineal gland clearly appeared to bind the mAbs.

\section{Discussion}

Our immunohistochemical results indicate that several different mAbs to functional neuronal AChRs label the same neural regions that bind ${ }^{3} \mathrm{H}$-nicotine (Clarke et al., 1985b; London et al., 1985), and that this labeling pattern is quite distinct from that for ${ }^{125} \mathrm{I}-\alpha \mathrm{Bgt}$ binding (Hunt and Schmidt, 1978; Clarke et al., 1985b). Furthermore, the results indicate that neuronal AChRs may undergo axonal transport in the optic nerve, the processes of sensory ganglion cells, the habenulointerpeduncular tract, and the nigrostriatal system, and suggest that this may also occur in a number of other central pathways (e.g., thalamocortical) that remain to be manipulated experimentally. This possibility is based, first, on the observation of immunolabeling in neuronal cell bodies, as well as in associated axonal pathways, where protein synthesis does not occur and, second, on the reduction of immunolabeling in terminal fields of the optic nerve following enucleation. Recently, similar experimental evidence has been reported for the possible transport of neuronal AChRs in the 


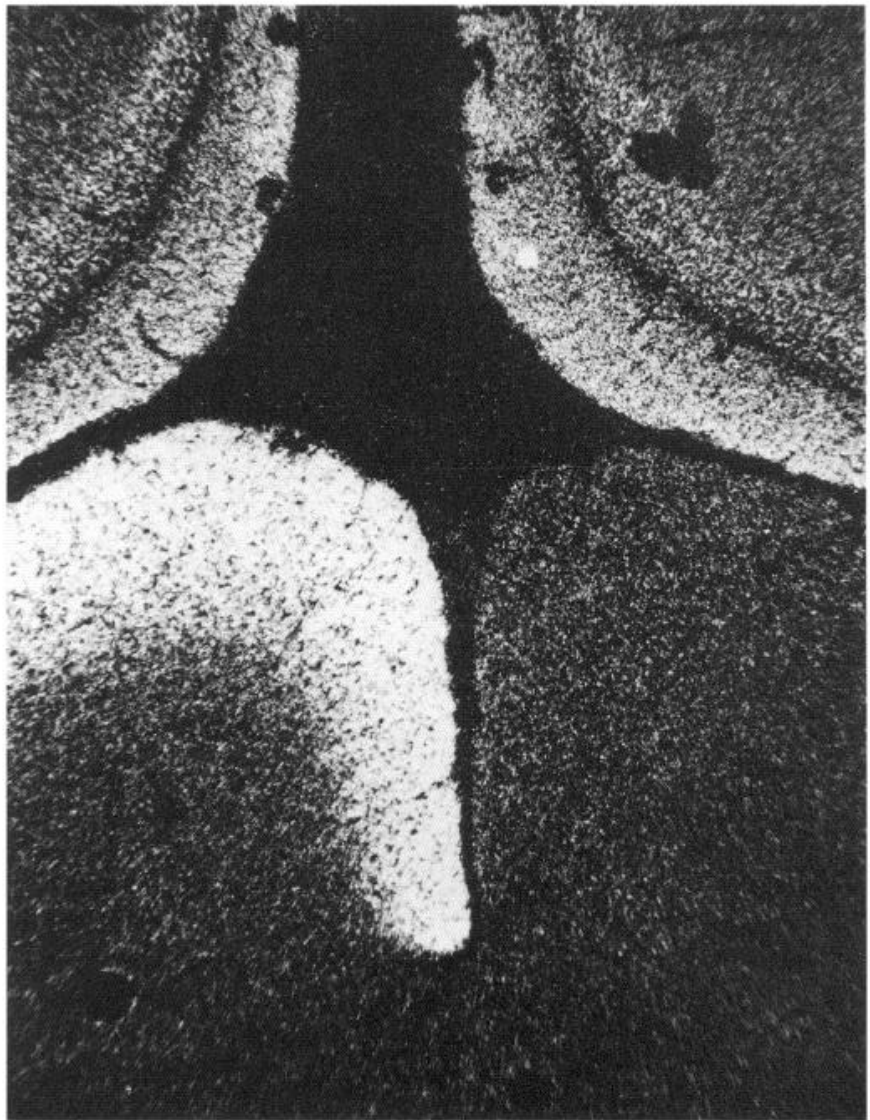

Figure 6. Dark-field photomicrographs showing the distribution on ${ }^{125} \mathrm{I}-\mathrm{mAb} 270$ labeling in the retrosplenial area (top) and superior colliculus (bottom) of an enucleated rat; section cut in the frontal plane. $\times 50$.

habenulointerpeduncular tract (Clarke et al., 1986), and it seems clear that a number of other putative neurotransmitter receptors may also undergo axonal transport (see Zarbin et al., 1982), although its functional significance is as yet unclear.

A well-studied example of possible neuronal AChR transport is the nigrostriatal dopamine system, where nigral cells are thought to receive a nicotinic cholinergic input, and dopamine release from striatal terminals can be pharmacologically modulated by presynaptic AChRs (see Giorguieff-Chesselet et al., 1979; Clarke and Pert, 1985; Clarke et al., 1985a, b). Nigral cells thus appear to synthesize and transport neuronal AChRs to both their dendrites and axon terminals. In other systems, however, it is possible that neurons may synthesize neuronal AChRs that are normally involved in dendritic synaptic transmission, with axonal transport to terminals that is nothing more than a routing "accident" with no physiological relevance. This may be the case with the peripheral branches of sensory ganglion cells that are excited by exogenous $\mathrm{ACh}$, but where a physiologically relevant source of transmitter is not clear (Gray, 1959; Paintal, 1964).

In brain regions that appear to contain presynaptic neuronal AChRs, it will be necessary to determine whether ACh is released either on (synaptic effect) or near (paracrine effect) the terminals. In this regard, it is important to point out that $\mathrm{ACh}$ levels have been measured biochemically in tissue punches from many parts of the rat brain (Cheney et al., 1975; Hoover et al., 1978), and while all parts of the CNS that bind mAbs to the neuronal AChR were not sampled in these studies, ACh was found in all of those that were sampled. Furthermore, immunohistochemical studies have shown a strong correlation for the presence of the synthetic enzyme choline acetyltransferase (ChAT) in regions that bind $\mathrm{mAbs}$ to the neuronal AChR (Armstrong et al., 1983; Houser et al., 1983; Mesulam et al., 1983; Wolf et al., 1983, 1984; Sofroniew et al., 1985a, b; Wolf and Butcher, 1986; also see Rotter and Jacobowitz, 1981), although here the data are less complete because many fine cholinergic axons have thus far proven difficult to stain with antibodies to ChAT. And finally, there is histochemical evidence (Koelle, 1954; Shute and Lewis, 1963, 1967; Storm-Mathisen and Blackstad, 1964; Lewis and Shute, 1967; Hoover and Jacobowitz, 1979; Hoover and Baisden, 1980; Paxinos and Watson, 1982; Satoh et al., 1983; Robertson et al., 1986) for the presence of the metabolic enzyme AChE in virtually all of the regions with labeling reported here. Thus, in many areas that bind mAbs to neuronal $\mathrm{AChR}$, there is also evidence for the presence of $\mathrm{ACh}$, ChAT, and AChE, although evidence for synapses (either preor postsynaptic) remains to be obtained using appropriate elec-
Figure 7. Dark-field photomicrograph illustrating the distribution of ${ }^{125} \mathrm{I}-$ $\mathrm{mAb} 270$ labeling in the hippocampus of the rat. Note that labeling is centered over the stratum lacunosum moleculare of Ammon's horn and the middle third of the dentate molecular layer, in the region innervated by the medial perforant path. $\times 60$.

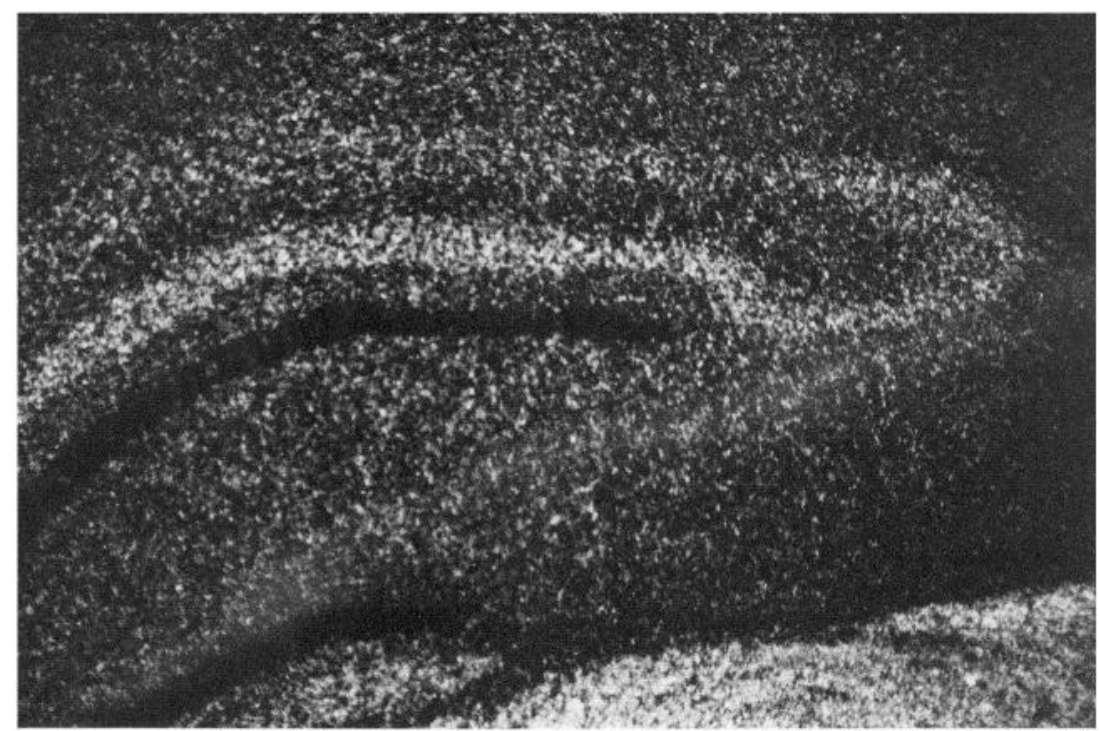


tron-microscopic and electrophysiological methods. In a highly collateralized system like the optic nerve, the possibility must also be entertained that neuronal AChRs may be distributed throughout the axonal tree of ganglion cells that express the receptor, whereas $\mathrm{ACh}$ release may occur in only some of the terminal fields. It will also be important to establish whether other neurotransmitters or endogenous ligands bind to and infiuence the function of neuronal AChRs.

Finally, it remains to be determined whether there is a single neuronal $\mathrm{AChR}$ in rodent brain, or whether there are families of neuronal AChRs with differences in subunit amino acid sequence and/or subunit stoichiometry, as now seem clearly to exist in the chicken (Whiting and Lindstrom, 1987b; Whiting et al., 1987a). As mRNAs for the subunits are cloned and sequenced, hybridization histochemistry can be used to localize cell bodies that synthesize these proteins, and indeed this approach has been used to demonstrate mRNA for a putative neuronal AChR in certain parts of the neocortex, thalamus, and midbrain identified here (Goldman et al., 1986). This approach will be particularly useful for distinguishing the location of cell bodies that synthesize receptor from the sites to which the receptor is transported by dendrites and axons. The latter can be approached immunohistochemically, but, as in the present study, areas of dense labeling may contain both labeled cell bodies and axon terminals, or just dense terminal labeling, that may be difficult to distinguish in some instances. In the future, a combination of immuno- and hybridization histochemical methods may be used to determine the sites of neuronal AChR(s) synthesis, as well as the distribution of $\mathrm{AChR}(\mathrm{s})$ within the dendrites and axons of particular cell groups, both at the light and electronmicroscopic (Jacob et al., 1984) levels.

\section{References}

Ariel, M., and N. W. Daw (1982) Pharmacological analysis of directionally sensitive rabbit retinal ganglion cells. J. Physiol. (Lond.) 324: 161-185.

Armstrong, D. M., C. B. Saper, A. I. Levy, B. H. Wainer, and R. D. Terry (1983) Distribution of cholinergic neurons in rat brain: Demonstrated by the immunocytochemical localization of choline acetyltransferase. J. Comp. Neurol. 216: 53-68.

Brecha, N., A. Francis, and N. Schechter (1979) Rapid loss of nicotinecholinergic receptor binding activity in the deafferented ovian optic lobe. Brain Res. 167: 273-280.

Cheney, D. L., H. F. LeFevre, and G. Racagni (1975) Choline acetyltransferase activity and mass fragmentographic measurement of acetylcholine in specific nuclei and tracts of rat brain. Neuropharmacology 14: 801-809.

Clarke, P. B. S., and A. Pert (1985) Autoradiographic evidence for nicotine receptors on nigrostriatal and mesolimbic dopaminergic neurons. Brain Res. 348: 355-358.

Clarke, P. B. S., D. W. Hommer, A. Pert, and L. R. Skirboll (1985a) Electrophysiological actions of nicotine on substantia nigra single units. Br. J. Pharmacol. 85: 827-835.

Clarke, P. B. S., R. D. Schwartz, S. M. Paul, C. B. Pert, and A. Pert (1985h) Nicotine binding in rat brain: Autoradiographic comparison of $\left[{ }^{3} \mathrm{H}\right]$ acetylcholine, $\left[{ }^{3} \mathrm{H}\right]$ nicotine, and $\left[{ }^{125} \mathrm{I}\right] \alpha$-bungarotoxin. J. Neurosci. 5: 1307-1315.

Clarke, P. B. S., G. S. Hamill, N. S. Nadi, D. M. Jacobowitz, and A. J. Pert (1986) ${ }^{3} \mathrm{H}$-nicotine and ${ }^{125} \mathrm{I}$-alpha-bungarotoxin-labeled nicotinic receptors in the interpeduncular nucleus of rats. II. Effects of habenular deafferentiation. J. Comp. Neurol. 251; 407-413.

Conti-Tronconi, B. M., S. M. J. Dunn, E. A. Barnard, J. O. Dolly, F. A. Lai, N. Ray, and M. A. Raftery (1985) Brain and muscle nicotinic acetylcholine receptors are different but homologous proteins. Proc. Natl. Acad. Sci. USA 82: 5208-5212.

Cooper, E., and M. J. Lau (1986) Factors affecting the expression of acetylcholine receptors on rat sensory neurones in culture. J. Physiol. (Lond.) 377: 409-420.
DeMontigny, C., and J. P. Lund (1980) A microiontophoretic study of the action of kainic acid and putative neurotransmitters in the rat mesencephalic trigeminal nucleus. Neuroscience 5: 1621-1628.

Esplin, D. W., R. Capek, and B. A. Esplin (1972) Pharmacological studies on dorsal root responses produced by ventral root stimulation in the cat. Can. J. Physiol. Pharmacol. 50: 119-122.

Feldberg, W., and P. G. Guertzenstein (1976) Vasodepressor effects obtained by drugs acting on the ventral surface of the brain stem. $J$. Physiol. (Lond.) 250: 337-355.

Giorguieff-Chesselet, M. F., M. L. Kemel, D. Wandscheer, and J. Glowinski (1979) Regulation of dopamine release by presynaptic nicotinic receptors in rat striatal slices: Effect of nicotine in a low concentration. Life Sci, 25: 1257-1262.

Goldman, D., D. Simmons, L. W. Swanson, J. Patrick, and S. Heinemann (1986) Mapping of brain areas expressing RNA homologous to two different acetylcholine receptor $\alpha$-subunit cDNAs. Proc. Natl. Acad. Sci. USA 83: 4076-4080.

Gray, V. A. B. (1959) Initiation of impulses at receptors. In Handbook of Physiology, vol. 1, sect. 1, J. Field and H. W. Magoun, eds., pp. 123-145, American Physiological Society, Baltimore, MD.

Hayhow, W. R., A. Sefton, and C. Webb (1982) Primary optic centers of the rat in relation to the terminal distribution of the crossed and uncrossed optic nerve fibers. J. Comp. Neurol. 118: 295-321.

Henley, J. M., J. M. Lindstrom, and R. E. Oswald (1986) Acetylcholine receptor synthesis in retina and transport to optic tectum in goldfish. Science 232: 1627-1629.

Herkenham, M., and C. B. Pert (1982) Light microscopic localization of brain opiate receptors: A general autoradiographic method which preserves tissue quality. J. Neurosci. 2: 1129-1149.

Hoover, D. B., and R. H. Baisden (1980) Localization of putative cholinergic neurons innervating the anteroventral thalamus. Brain Res. 5: 519-524.

Hoover, D. B., and D. M. Jacobowitz (1979) Neurochemical and histochemical studies of the effect of a lesion of the nucleus cuneiformis on the cholinergic innervation of discrete areas of the rat brain. Brain Res. 170: 113-122.

Hoover, D. B., E. A. Muth, and D. M. Jacobowitz (1978) A mapping of the distribution of acetylcholine, choline acetyltransferase, and acetylcholinesterase in discrete areas of rat brain. Brain Res. 153: 295-306.

Houser, C. R., G. D. Crawford, R. P. Barber, P. M. Salvaterra, and J. E, Vaughn (1983) Organization and morphological characteristics of cholinergic neurons: An immunocytochemical study with a monoclonal antibody to choline acetyltransferase. Brain Res. 266: 97-119.

Hunt, S., and J. Schmidt (1978) Some observations on the binding patterns of $\alpha$-bungarotoxin in the central nervous system of the rat. Brain Res. 157: 213-232.

Ikeda, H., and M. J. Sheardown (1982) Acetylcholine may be an excitatory transmitter mediating visual excitation of "transient" cells with the periphery effect in the cat retina: Iontophoretic studies in vivo. Neuroscience 7: 1299-1308.

Jacob, M. H., D. K. Berg, and J. M. Lindstrom (1984) Shared antigenic determinant between the Electrophorus acetylcholine receptor and a synaptic component on chicken ciliary ganglion neurons. Proc. Natl. Acad. Sci. USA 81: 3223-3227.

Karczmar, A. G., S. Nishi, S. Minota, and G. Kindel (1980) Electrophysiology of acetylcholine and acetylcholinesterase of immature spinal ganglion of the rabbit-an experimental study and a review. Gen. Pharmacol. 11: 127-134.

Kemp, G., L. Bentley, M. McNamee, and B. J. Morley (1985) Purification and characterization of the $\alpha$-bungarotoxin binding protein from rat brain. Brain Res. 347: 274-283.

Koelle, G. B. (1954) The histochemical localization of cholinesterases in the central nervous system of the rat. J. Comp. Neurol. 100: 211235.

Kokko, A. (1965) Histochemical and cytophotometric observations on esterases in the spinal ganglion of the rat. Acta Physiol. Scand. (Suppl. 261) 66: 1-76.

Kubo, T., K. Fukuda, A. Mikami, A. Maeda, H. Takahasi, M. Mishina, T. Haga, K. Haga, A. Ichiyama, K. Kangawa, M. Kojima, H. Matsuo, T. Hirose, and S. Numa (1986a) Cloning, sequencing and expression of complementary DNA encoding the muscarinic acetylcholine receptor. Nature 323: 411-416.

Kubo, T., K. Fukuda, A. Mikami, A. Maeda, H. Takahasi, M. Mishina, T. Haga, K. Haga, A. Ichiyama, K. Kangawa, M. Kojima, H. Matsuo, 
T. Hirose, and S. Numa (1986b) Primary structure of porcine cardiac muscarinic acetylcholine receptor deduced from the cDNA sequence. FEBS Lett. 209: 367-372.

Lewis, P. R., and C. C. D. Shute (1967) The cholinergic limbic system: Projections to the hippocampal formation, medial cortex, nuclei of the ascending cholinergic reticular system, and the subfornical organ and supra-optic crest. Brain 90:521-543.

Lindstrom, J. M. (1986) Probing nicotinic acetylcholine receptors with monoclonal antibodies. Trends Neurosci. 9: 401-407.

Lindstrom, J., B. Einarson, and S. Tzartos (1981) Production and assay of antibodies to acetylcholine receptors. Methods Enzymol. 74: 432-460.

Lipton, S. A., E. Aizenman, and D. L. Tauck (1986) Patch-clamp recordings of nicotinic cholinergic responses in solitary rat retinal ganglion cells in culture. Soc. Neurosci. Abstr. 12: 635.

London, E. D., S. B. Walles, and J. K. Wamsley (1985) Autoradiographic localization of $\left[{ }^{3} \mathrm{H}\right]$ nicotine binding sites in the rat brain. Neurosci. Lett. 53: 179-184.

Mason, W. T. (1985) Staining of the magnocellular nuclei of the rat hypothalamus by a monoclonal antibody directed against the $\alpha$-subunit of the nicotinic cholinergic receptor. Neurosci. Lett. 59: 89-95.

McCarthy, M. P., J. P. Ernest, E. F. Young, S. Choe, and R. M. Stroud (1986) The molecular neurobiology of the acetylcholine receptor. Annu. Rev. Neurosci. 9: 383-413.

Mesulam, M.-M., E. J. Mufson, B. H. Wainer, and A. I. Levey (1983) Central cholinergic pathways in the rat: An overview based on an alternative nomenclature (Ch1-Ch6). Neuroscience 10: 1185-1201.

Noda, M., Y. Furutani, H. Takahashi, M. Toyosato, T. Tanabe, S. Shimizu, S. Kikyotani, T. Kanayo, T. Hirose, S. Inayama, and $S$. Numa (1983a) Cloning and sequence analysis of calf cDNA and human genomic DNA encoding $\alpha$ subunit precursor of muscle acetylcholine receptor. Nature 305: 818-823.

Noda, M., H. Takahashi, T. Tanabe, M. Toyosato, S. Kikyotani, Y. Furutani, Y. Hirose, H. Takashima, S. Inayama, T. Miyata, and S. Numa (1983b) Structural homology of Torpedo californica receptor subunits. Nature 302: 528-532.

Paintal, A. S. (1964) Effects of drugs on vertebrate mechanoreceptors. Pharmacol. Rev. 16: 341-380.

Patrick, J., and W. B. Stallcup (1977) Immunological distinction between acetylcholine receptor and the $\alpha$-bungarotoxin binding component on sympathetic neurons. Proc. Natl. Acad. Sci. USA 74:46894692.

Paxinos, G., and C. Watson (1982) The Rat Brain in Stereotaxic Coordinates, Academic, Sydney.

Pazdernik, T. L., R. S. Cross, K. Mewes, F. Samson, and S. R. Nelson (1982) Superior colliculus activation by retinal nicotinic ganglion cells: A 2-deoxyglucose study. Brain Res. 243: 197-200.

Polz-Tejera, G., S. P. Hunt, and J. Schmidt (1980) Nicotinic receptors in sensory ganglion. Brain Res. 195: 223-230.

Popot, J.-L., and J. P. Changeux (1984) Nicotinic receptor of acetylcholine: Structure of an oligomeric membrane protein. Physiol. Rev. 64: 1162-1239.

Robertson, R. T., C. L. Lieu, K. Lee, and C. Gorenstein (1986) Distribution of "non-specific" cholinesterase-containing neurons in the dorsal thalamus of the rat. Brain Res. 368: 116-124.

Rotter, A., and D. M. Jacobowitz (1981) Neurochemical identification of cholinergic forebrain projection sites of the nucleus tegmentalis dorsalis lateralis. Brain Res. Bull. 6: 525-529.

Satoh, K., D. M. Armstrong, and H. C. Fibiger (1983) A comparison of the distribution of central cholinergic neurons as demonstrated by acetylcholinesterase pharmacohistochemistry and choline acetyltransferase immunohistochemistry. Brain Res. Bull. 11: 693-720.

Sawchenko, P. E., and L. W. Swanson (1983) The organization of forebrain afferents to the paraventricular and supraoptic nuclei of the rat. J. Comp. Neurol. 218: 121-144.

Shipley, M. T., and K. E. Sørensen (1975) On the laminar organization of the anterior thalamus projections to the presubiculum in the guinea pig. Brain Res. 86: 473-477.
Shute, C. C. D., and P. R. Lewis (1963) Cholinesterase-containing systems of the brain of the rat. Nature 199: 1160-1164.

Shute, C. C. D., and P. R. Lewis (1967) The ascending cholinergic reticular system: Neocortical, olfactory and subcortical projections. Brain 90: 497-521.

Sofroniew, M. V., P. E. Campbell, A. C. Cuello, and F. Eckenstein (1985a) Central cholinergic neurons visualized by immunohistochemical detection of choline acetyltransferase. In The Rat Nervous System, vol. 1: Forebrain and Midbrain, G. Paxinos, ed., pp. 471485, Academic, Sydney.

Sofroniew, M. V., J. V. Priestly, A. Consolazione, F. Eckenstein, and A. C. Cuello (1985b) Cholinergic projections from the midbrain and pons to the thalamus in the rat, identified by combined retrograde tracing and choline acetyltransferase immunohistochemistry. Brain Res. 329: 213-223.

Stollberg, J., P. J. Whiting, J. M. Lindstrom, and D. K. Berg (1986) Functional blockade of neuronal acetylcholine receptors by antisera to a putative receptor from brain. Brain Rcs. 378: 179-182.

Storm-Mathisen, J., and T. W. Blackstad (1964) Cholinesterase in the hippocampal region. Acta Anat. 56: 216-253.

Swanson, L. W., J. Lindstrom, S. Tzartos, L. Schmued, D. D. O'Leary, and W. M. Cowan (1983a) Immunohistochemical localization of monoclonal antibodies to the nicotinic acetylcholine receptor in the midbrain of the chick. Proc. Natl. Acad. Sci. USA 80: 4532-4536.

Swanson, L. W., P. E. Sawchenko, J. Rivier, and W. W. Vale (1983b) Organization of ovine corticotropin-releasing factor immunoreactive cells and fibers in the rat brain: An immunohistochemical study. Neuroendocrinology $36: 165-186$.

Voigt, T. J. (1986) Cholinergic amacrine cells in the rat retina. J. Comp Neurol. 248: 19-35.

Whiting, P. J., and J. M. Lindstrom (1986a) Purification and characterization of a nicotinic acetylcholine receptor from chick brain. Biochemistry 25: 2082-2093.

Whiting, P. J., and J. M. Lindstrom (1986b) Pharmacological properties of immuno-isolated neuronal nicotinic receptors. J. Neurosci. 6: 3061-3069.

Whiting, P. J., and J. M. Lindstrom (1987a) Purification and characterization of a nicotinic acetylcholine receptor from rat brain. Proc. Natl. Acad. Sci. USA 84: 595-599.

Whiting, P., and J. Lindstrom (1987b) Affinity labeling of neuronal acetylcholine receptors localizes acetylcholine binding sites to their $\beta$ subunits. FEBS Lett. 213: 55-60.

Whiting, P. J., R. Liu, B. J. Morley, and J. M. Lindstrom (1987a) Structurally different neuronal nicotinic acetylcholine receptor subtypes purified and characterized using monoclonal antibodies. J. Neurosci. (in press).

Whiting, P. J., R. Schoepfer, L. W. Swanson, D. M. Simmons, and J. M. Lindstrom (1987b) Functional acetylcholine receptor in PC12 cells reacts with a monoclonal antibody to brain nicotinic receptors. Nature 327: 515-518.

Woolf, N. J., and L. L. Butcher (1986) Cholinergic systems in the rat brain. III. Projections from the pontomesencephalic tegmentum to the thalamus, tectum, basal ganglia, and basal forebrain. Brain Res. Bull. 16: 603-637.

Woolf, N. J., F. Eckenstein, and L. L. Butcher (1983) Cholinergic projections from the basal forebrain to the frontal cortex: A combined fluorescent tracer and immunohistochemical analysis in the rat. Neurosci. Lett. 40: 93-98.

Woolf, N. J., F. Eckenstein, and L. L. Butcher (1984) Cholinergic systems in the rat brain. I. Projections to the limbic telencephalon. Brain Res. Bull. 13: 751-784.

Wu, K. M., and W. R. Martin (1983) An analysis of nicotinic and opioid processes in the medulla oblongata and nucleus ambiguus of the dog. J. Pharmacol. Exp. Ther. 227: 302-307.

Zarbin, M. A., J. K. Wamsley, and M. J. Kuhar (1982) Axonal transport of muscarinic cholinergic receptors in rat vagus nerve: High and low affinity agonist receptors move in opposite directions and differ in nucleotide sensitivity. J. Neurosci. 2: 934-941. 